This item was submitted to Loughborough's Research Repository by the author.

Items in Figshare are protected by copyright, with all rights reserved, unless otherwise indicated.

\title{
Effect of thermal aging on interfacial behaviour of copper ball bonds
}

PLEASE CITE THE PUBLISHED VERSION

PUBLISHER

(C) IEEE

VERSION

VoR (Version of Record)

LICENCE

CC BY-NC-ND 4.0

REPOSITORY RECORD

Xu, Hui, Changqing Liu, and Vadim V. Silberschmidt. 2019. "Effect of Thermal Aging on Interfacial Behaviour of Copper Ball Bonds". figshare. https://hdl.handle.net/2134/5334. 
This item was submitted to Loughborough's Institutional Repository (https://dspace.lboro.ac.uk/) by the author and is made available under the following Creative Commons Licence conditions.

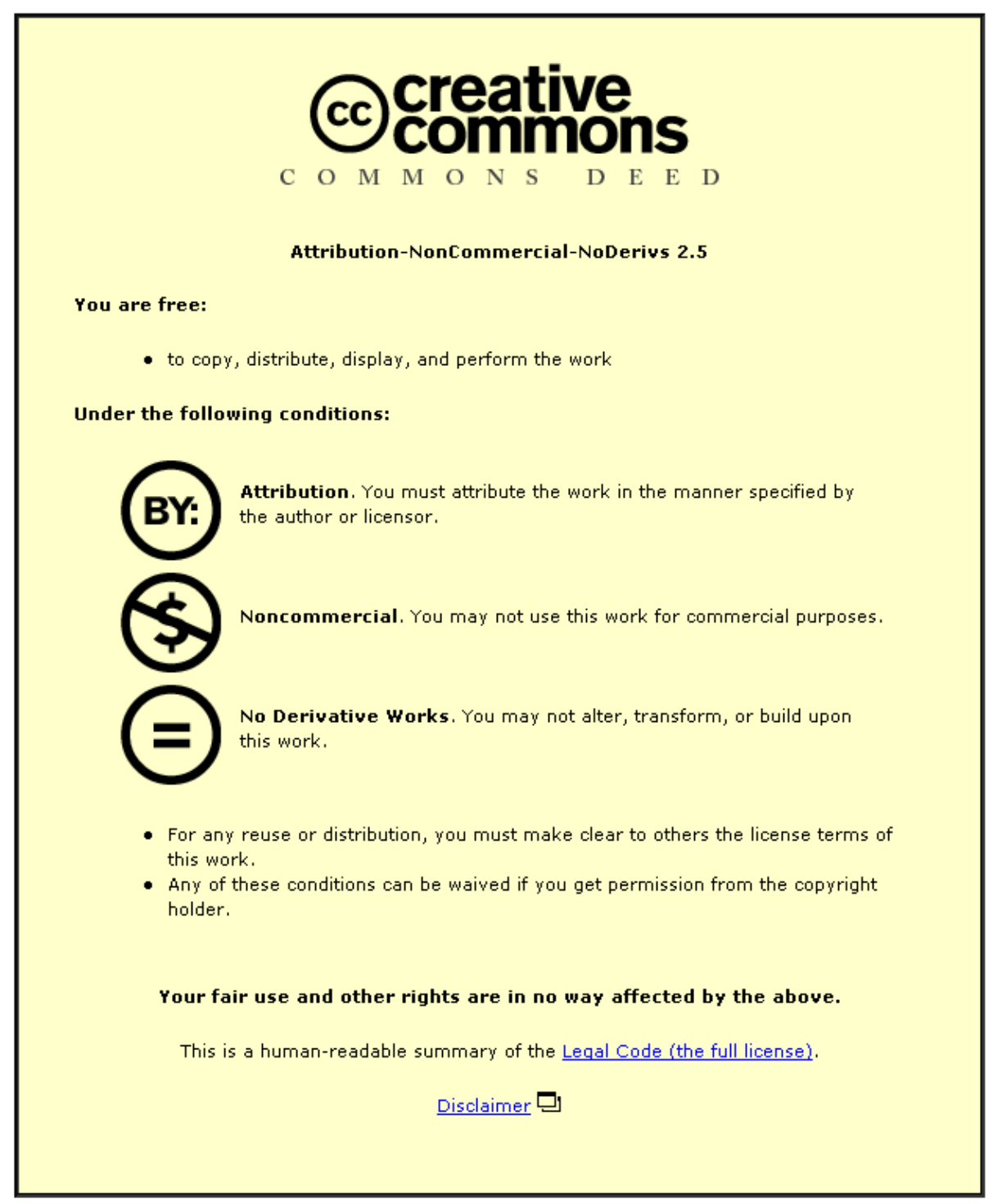

For the full text of this licence, please go to: http://creativecommons.org/licenses/by-nc-nd/2.5/ 


\title{
Effect of Thermal Aging on Interfacial Behaviour of Copper Ball Bonds
}

\author{
Hui Xu, Changqing Liu, Vadim Silberschmidt \\ Wolfson School of Mechanical and Manufacturing Engineering, Loughborough University, \\ Loughborough, LE11 3TU, UK \\ E-mail: H.Xu3@lboro.ac.uk, Phone: +44-1509-227684
}

\begin{abstract}
Thermosonic copper ball bonding is an interconnection technology that serves as a viable and cost-saving alternative to gold ball bonding. However, the reliability of copper bonds remains to be ascertained. Intermetallic compounds (IMCs) and possible voids and cracks may grow and propagate at the interface of bonds during their service. The proper IMCs formation is beneficial to bonding strength but an excessive growth of IMCs, voids and cracks can induce a mechanical failure and increase a contact resistance.

In this study, a $99.99 \%$ copper wire with diameter $50.4 \mu \mathrm{m}$ was bonded to a $\mathrm{Al}-1 \% \mathrm{Si}-0.5 \% \mathrm{Cu}$ metallisation pad by thermosonic bonding. Scanning electron microscopy, energy dispersive X-ray spectrometry, dual focused ion bean and transmission electron microscopy (TEM) were used to investigate the interfacial evolution of such formed joints during the thermal ageing, and kinetics of $\mathrm{Cu}-\mathrm{Al}$ IMCs growth was established. The results showed no IMCs at the initial bonded $\mathrm{Cu} / \mathrm{Al}$ interface. To study the $\mathrm{Cu}-\mathrm{Al}$ IMCs growth, the samples were thermally aged for different times at a temperature from $200{ }^{\circ} \mathrm{C}$ to $300{ }^{\circ} \mathrm{C}$ to accelerate interfacial evolution. The growth of $\mathrm{Cu}-\mathrm{Al}$ IMCs followed the parabolic law as a function of aging time at a certain aging temperature, and it is more sensitive to temperature compared to time. The activation energy of $\mathrm{Cu}-\mathrm{Al}$ IMC growth was obtained from the Arrhenius plot. Voids and cracks, which are commonly present in gold ball bonds due to thermal aging, were not observed in copper ball bonds even after aging at $200{ }^{\circ} \mathrm{C}$ for 2900 hours. Finally, the structure of $\mathrm{Cu}-\mathrm{Al}$ IMCs was confirmed to be $\mathrm{Cu}_{9} \mathrm{Al}_{4}$ by selected area electron diffraction with TEM.
\end{abstract}

\section{Introduction}

As the first-level packaging technology, wire bonding provides electrical interconnection between the bond pads on IC chips and the leads on package using fine metal wires. Owing to its potentially low cost, its much improved yields and reliability, wire bonding has been used with all styles of microelectronic packages, accounting for over $90 \%$ of the entire chip-to-package interconnections formed [1]. According to the energy input, there are three kinds of wire bonding technologies: thermocompression bonding, ultrasonic bonding and thermosonic bonding. Thermosonic bonding is the most widely used for electrical and signal interconnections of the integrated circuit chip packages, through a combination of thermocompression and ultrasonic bonding for an optimized their performance/properties.
As has been commonly used in thermosonic bonding, with ultrasonic vibration, pressure loading and thermal implementing, the gold wire is bonded onto die metallisation (typically, an aluminum pad). However, this bonding process can easily lead to formation of $\mathrm{Au}-\mathrm{Al}$ intermetallic compounds (IMCs) with the associated Kirkendall voids. Therefore, this often presents a reliability problem in the bonds [1-4]. The use of $\mathrm{Cu}$ wire for thermosonic ball bonding presents several advantages with regard to Au wire [5-7]. These advantages include: 1) cost reduction of up to $90 \%$; 2 ) superior electrical and thermal conductivity; 3) lower intermetallic growths; 4) greater reliability of the bond at elevated temperatures; and 5) higher mechanical stability. Copper wire bonding can be a potential alternative interconnection technology along with flip chip interconnection.

IMCs formation and related voids and cracks at the interface determine the strength and reliability of the bonds. The IMCs formation is beneficial to bonding strength but their excessive growth can increase brittleness of bonds and the contact resistance, thus leading to bonds failure. In gold ball bonding, a typical 2000-5000 $\AA$ layer of intermetallic is said to form between the gold ball and the aluminum metallisation during bonding [8]. This initial Au-Al IMCs can grow thicker during molding and device operation due to thermally activated reactive diffusion, causing mechanical and electrical failure, known as 'purple plague' [1]. In the case of $\mathrm{Cu} / \mathrm{Al}$ bond system, however, identification of the $\mathrm{Cu}-\mathrm{Al}$ IMCs is difficult $[1,2,9]$. Kim et al. showed that the growth rate of $\mathrm{Cu} / \mathrm{Al}$ IMCs was about $1 / 10$ of that of $\mathrm{Au} / \mathrm{Al}$ in the temperature range of $150{ }^{\circ} \mathrm{C}-300{ }^{\circ} \mathrm{C}$ [10]. $\mathrm{Cu}-\mathrm{Al}$ IMCs formation during thermal aging was reported using a welded diffusion couple of bulky copper and aluminium $[9,11]$ or a thin-film $\mathrm{Cu} / \mathrm{Al}$ diffusion couple $[12,13]$. According to the binary phase diagram of the $\mathrm{Cu}-\mathrm{Al}$ system, five IMCs (i.e. $\mathrm{CuAl}_{2}(\theta), \operatorname{CuAl}\left(\eta_{2}\right)$, $\mathrm{Cu}_{4} \mathrm{Al}_{3}\left(\zeta_{2}\right), \mathrm{Cu}_{3} \mathrm{Al}_{2}(\delta)$ and $\left.\mathrm{Cu}_{9} \mathrm{Al}_{4}\left(\gamma_{2}\right)\right)$ can be formed at temperatures from $150{ }^{\circ} \mathrm{C}-300{ }^{\circ} \mathrm{C}$ [10]. Due to the slow growth of IMCs, a small amount of Cu-Al IMCs is difficult to detect with conventional analysis equipment. Therefore, the possible $\mathrm{Cu}-\mathrm{Al}$ IMCs structure has not yet been identified.

In this study, the copper bonds on $\mathrm{Al}-1 \% \mathrm{Si}-0.5 \% \mathrm{Cu}$ metallisation under various thermal aging trails were carried out. The growth behaviour of Cu-Al IMCs at the interface of such bonds was investigated in details in order to understand its kinetics. Meanwhile, the IMC phases in those bonds have also been determined using cross-sectional TEM foils prepared by a dual focused ion beam (FIB) system. 


\section{Experimental Procedures}

The ball bonds in this study were produced on the silicon chips with a $3 \mu \mathrm{m} \mathrm{Al}-1 \% \mathrm{Si}-0.5 \% \mathrm{Cu}$ metallisation layer using a $50.4 \mu \mathrm{m}(2 \mathrm{mil})$ diameter copper wire of $99.99 \%$ purity. The bonding process was carried out using an ASM Eagle 60 ball/wedge automatic bonder with frequency $148 \mathrm{kHz}$. A protective shielding gas (i.e. $95 \% \mathrm{~N}_{2}-5 \% \mathrm{H}_{2}$ ) was used through a copper kit in order to prevent the copper ball from oxidisation during the electrical flame off (EFO) process. The detailed bonding parameters for first copper bonds are shown in Table 1.

Table 1 Bonding parameters of first copper bonds

\begin{tabular}{c|c}
\hline Ultrasonic power $(\mathrm{mW})$ & 230 \\
\hline Bonding force $(\mathrm{gf})$ & 60 \\
\hline Bonding time $(\mathrm{ms})$ & 25 \\
\hline Initial temperature $\left({ }^{\circ} \mathrm{C}\right)$ & 220 \\
\hline
\end{tabular}

The bonds were then encapsulated in the EME-G700 green mold compound. In order to accelerate interfacial evolution and to study kinetics of $\mathrm{Cu}-\mathrm{Al}$ IMCs growth, samples were thermally aged at $200{ }^{\circ} \mathrm{C}$ for up to 121 days, $250{ }^{\circ} \mathrm{C}$ for up to $169 \mathrm{hrs}$ and $300{ }^{\circ} \mathrm{C}$ for up to 16 hrs. Cross-sectional scanning electron microscopy (SEM) samples were then prepared by grinding with small grit size 2000 paper, then polishing with $1.0 \mu \mathrm{m}, 0.25 \mu \mathrm{m}$ diamond suspension on silk cloths.

A HITACHI S-4700 SEM, equipped with energy dispersive X-ray spectrometry (EDS), was used for secondary electron (SE) and back-scatter electron (BE) imaging to investigate $\mathrm{Cu}-\mathrm{Al}$ IMCs. IMCs thickness measurements were performed at whole bonding interface of the bonds, and an average value was used for evaluation. The TEM samples were prepared from the copper ball bonded samples using the lift-out technique with Dual FIB [12]. One of the advantages of the dual FIB is that no mechanical force is applied during sample preparation, and the analysed region can be chosen using the SEM mode of the system. TEM analysis was finally carried out using a JEOL 2000FX with EDS.

\section{Results and Discussion}

3.1 As-bonded copper interfaces

Thermosonic ball bonding processes use a combination of heat, pressure, and ultrasonic energy to make an interconnection between an IC inner circuit and a leadframe. The process is typically finished within $5-30 \mathrm{~ms}$. Figure 1 shows a cross-sectional image of the $\mathrm{Cu} / \mathrm{Al}$ interface of copper bonds on the aluminium metallisation pad. It has appeared to be very difficult to identify any IMCs by SEM observation from the as-bonded copper joint. Line EDS for the composition distribution analysis near the interface in Figure 2 shows that copper or aluminium increased or decreased across the interface drastically, which indicates no significant inter-diffusion between copper and aluminium.

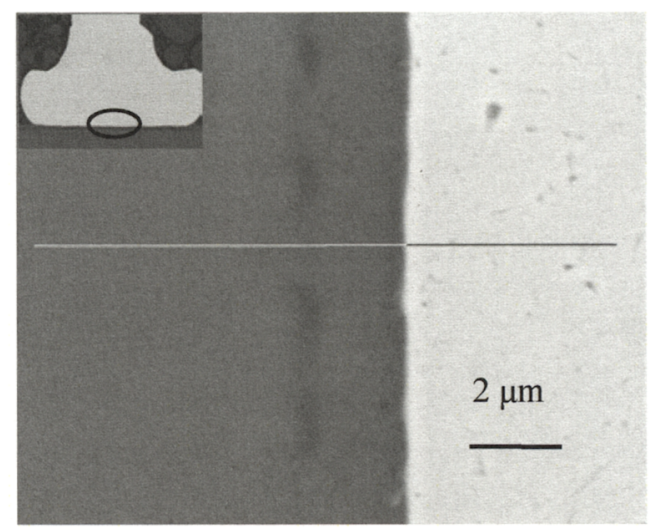

Figure 1 SEM image of cross-section of copper bonds on aluminum metallisation (see Table 1 for bonding parameters)

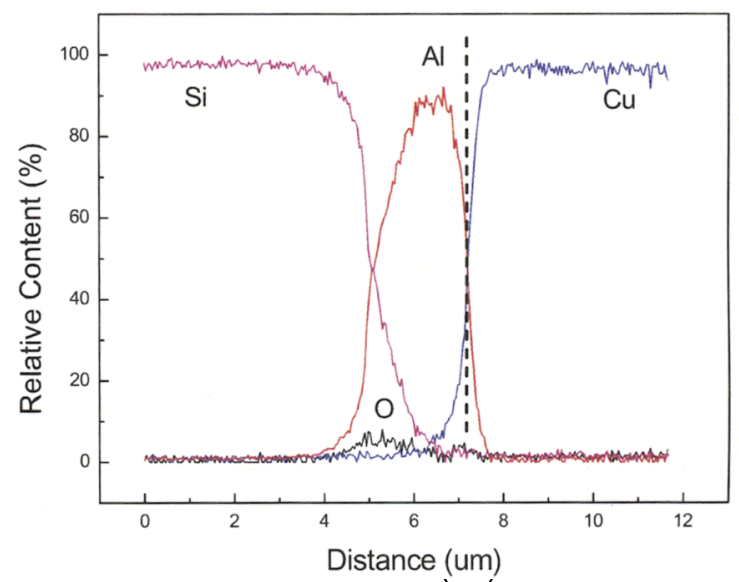

Figure 2 EDS line scan results for bond cross-section in Figure 1

\subsection{IMCs growth during thermal aging}

IMCs growth occurs during post-molding and device service trails, which can result in bond failure. In order to investigate the reliability of the $\mathrm{Cu}-\mathrm{Al}$ system, bonds were aged for different periods of time at different elevated temperatures.

The morphological changes that occur during thermal ageing at $200{ }^{\circ} \mathrm{C}$ are apparent in SEM micrographs in Figures 3a-d. Figure 3a presents BE SEM micrographs of samples aged for $1 \mathrm{~h}$, showing insignificant formation of $\mathrm{Cu}-\mathrm{Al}$ IMCs at the interface. $\mathrm{Cu}-\mathrm{Al}$ IMCs thickened with aging time (Figures $3 b-c$ ) but with low growth rate. IMCs thickness reached only about $1.5 \mu \mathrm{m}$ even after 121 days of aging, and no Kirkendall voids and cracks were formed at the interface (Figure 3d).

When aged at $250^{\circ} \mathrm{C}$, as shown in Figure 4a-d, the growth rate of IMCs increased. IMCs delaminated with the aging time, and layers of IMCs were clearly observed after $25 \mathrm{hrs}$ of aging. Al metallisation was consumed due to its reaction with copper, and was completely consumed after $169 \mathrm{hrs}$. 
(a)

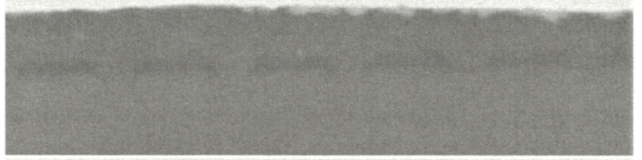

(b)

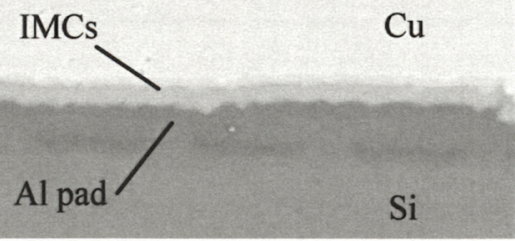

(c)

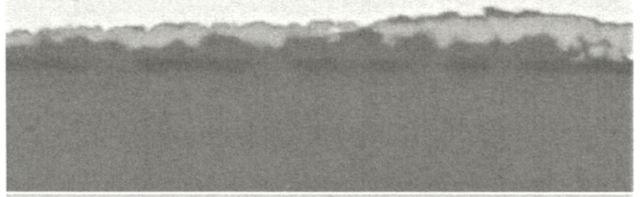

(d)

Figure 3 Cross sectional SEM of copper wire ball / $\mathrm{Al}$ metallisation interfaces after ageing at $200{ }^{\circ} \mathrm{C}$ for (a) 1 day, minor IMC formed; (b) 4 days, a layer of IMCs formed; (c) 64 days, a thicker IMCs ; and (d) 121 days, only $1.5 \mu \mathrm{m}$ thick IMCs formed, no Kirkendall voids and cracks observed (here and below, $\mathrm{Si}$ indicates a chip component, independent of $\mathrm{Al} \mathrm{pad}$ ).
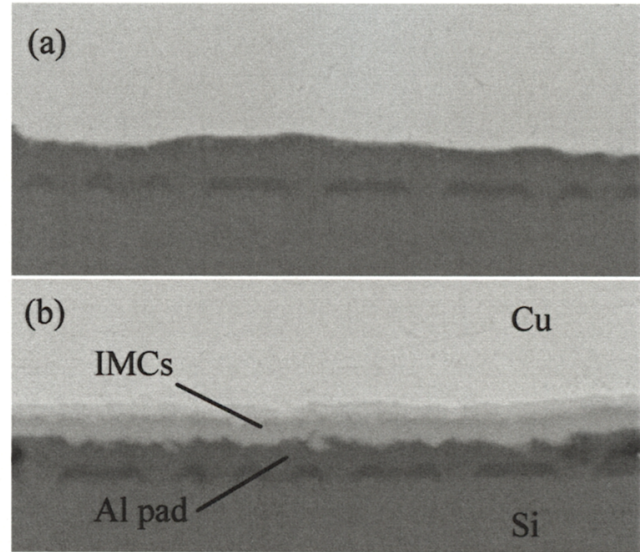

(c)

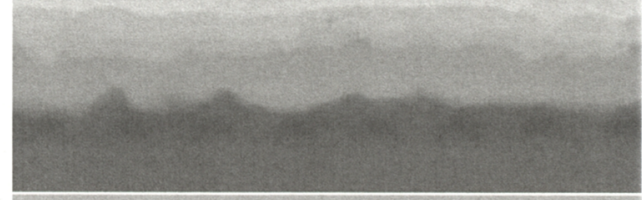

(d)

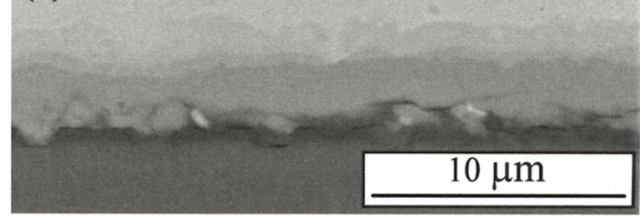

Figure 4 Cross sectional SEM of interfaces between copper wire ball / $\mathrm{Al}$ metallisation after aged at $250^{\circ} \mathrm{C}$ for: (a) 1 hour; (b) $25 \mathrm{hrs;} \mathrm{(c)} 100 \mathrm{hrs;} \mathrm{(d)} 169 \mathrm{hrs}$. Al alloy layer thinned with increasing time and disappeared after $169 \mathrm{hrs}$.
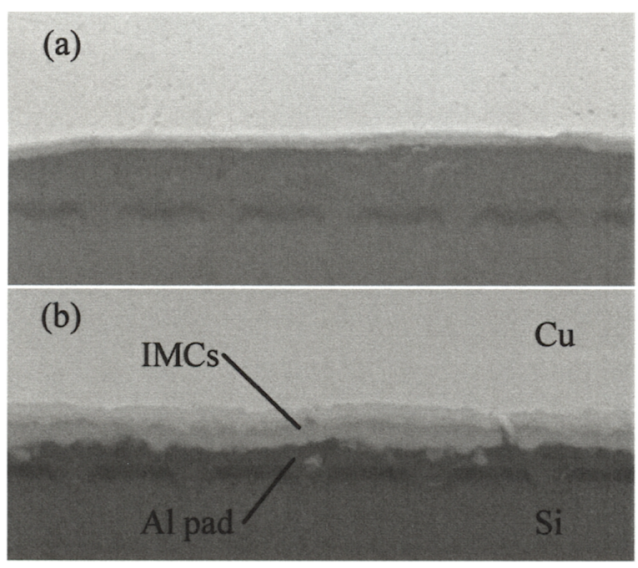

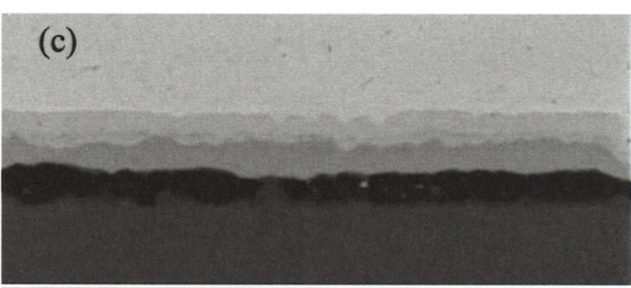

(d)

Figure 5 Cross sectional SEM images of the samples aged at $300^{\circ} \mathrm{C}$ for $1 \mathrm{~h} \mathrm{(a),} 4 \mathrm{~h}(\mathrm{~b}), 9 \mathrm{~h}(\mathrm{c})$ and $16 \mathrm{~h}(\mathrm{~d})$.

Figure 5 demonstrates the cross-sectional images of $\mathrm{Cu} / \mathrm{Al}$ IMCs formed at the bonding interface after thermal aging at $300{ }^{\circ} \mathrm{C}$. The IMCs became obvious at the $\mathrm{Cu} / \mathrm{Al}$ interface even after 1 hour of aging, and
IMCs increased rapidly with the aging time. Aluminum metallisation was almost consumed only after $16 \mathrm{hrs}$ of aging. The copper ball was detached after further thermal aging. 


\subsection{Kinetics of $\mathrm{Cu} / \mathrm{Al}$ IMCs growth}

In a solid-state reaction process, the initial growth rate of IMCs can be estimated using the following equation [3]:

$$
x=\left(K t+x_{1}\right)^{\frac{1}{n}}
$$

where $x$ is the IMC layer thickness, $t$ is the aging time, $x_{1}$ is a constant related to the initial IMC thickness after bonding, $K$ is the growth rate of IMCs and $n$ is the time index.

The value of growth rate of IMCs changes for different intermetallic phases, and is also dependent upon the neighboring phases, which supply additional $\mathrm{Cu}$ and Al for continued compound formation. However, it is extremely difficult to measure the IMCs thickness of each layer as they intertwine with each other, therefore, a generic growth rate of IMCs and a generic activation energy that combines the effects of all potential $\mathrm{Cu}-\mathrm{Al}$ IMCs formed at the interface had to be introduced. The growth rate of $\mathrm{Cu}-\mathrm{Al} \mathrm{IMCs}$ was determined by measuring the thickness of the inter-diffusion layers after thermal aging. Figure 6 shows the relations between thickness of IMCs formed at $\mathrm{Cu} / \mathrm{Al}$ interface and the aging time at 200 ${ }^{\circ} \mathrm{C}, 250{ }^{\circ} \mathrm{C}$, and $300{ }^{\circ} \mathrm{C}$. It was found that the growth of IMCs was determined by the aging temperature and aging time, and it was more sensitive to the aging temperature. $\mathrm{Cu}-\mathrm{Al}$ IMCs grew faster at the earlier stage. Furthermore, the IMC growth follows a parabolic law, with a time index of 2, and it was confirmed that the growth of $\mathrm{Cu}-\mathrm{Al}$ IMCs was diffusion controlled. The growth rate of $\mathrm{Cu}-\mathrm{Al}$ IMCs shown in Table 2 can be obtained from the fitting parabolas in Figure 6.

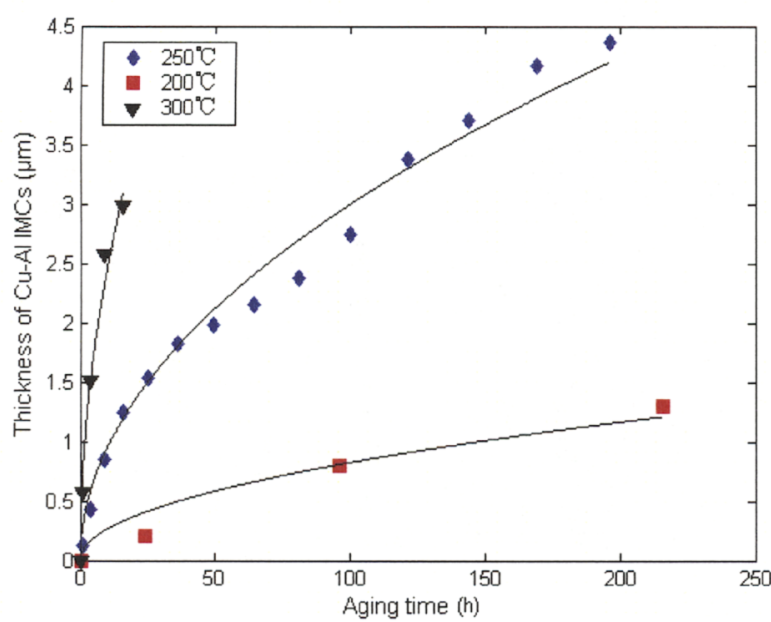

Figure 6 Effect of aging time on thickness of $\mathrm{Cu}$-Al IMCs at different temperatures
Table 2 Growth rates of $\mathrm{Cu}-\mathrm{Al}$ IMCs at different temperatures

\begin{tabular}{c|c}
\hline$T$, Temperature $\left({ }^{\circ} \mathrm{C}\right)$ & $\begin{array}{c}K, \text { Growth rate of Cu-Al IMCs } \\
\left(\mathrm{m}^{2} / \mathrm{s}\right)\end{array}$ \\
\hline 200 & $2.27 \times 10^{-18}$ \\
\hline 250 & $2.46 \times 10^{-17}$ \\
\hline 300 & $1.67 \times 10^{-16}$ \\
\hline
\end{tabular}

The growth rate of IMCs is characterized by the temperature and activation energy, and it can be given by the Arrhenius equation:

$K=K_{0} \exp \left(-\frac{Q}{R T}\right)$

where $K_{0}$ is a constant, $Q$ is the activation energy for IMCs growth, $R=8.314 \mathrm{~J} /(\mathrm{K} \times \mathrm{mol})$ is the Boltzmann constant, , and $T$ is the absolute temperature.

The generic activation energy, $Q$, can be calculated from the slope of a $\ln K-1 / T$ curve shown in Figure 7. The obtained activation energy was $97.1 \mathrm{~kJ} / \mathrm{mol}$, which was slightly different from the reported activation energy, $119.5-140.0 \mathrm{~kJ} / \mathrm{mol}$, obtained from the bulk $\mathrm{Cu} / \mathrm{Al}$ diffusion couple $[10,11]$.

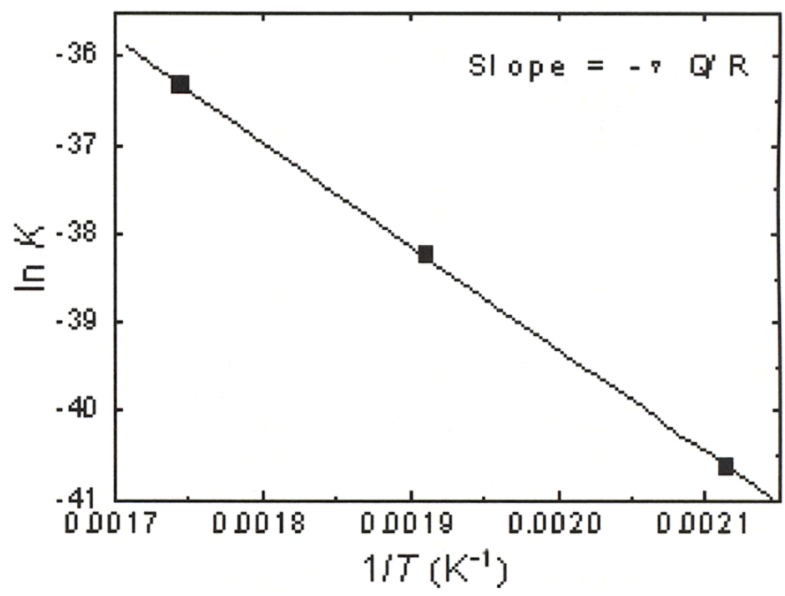

Figure $7 \ln K$ versus $1 / T$ dependence

As a result, the universal equation of $\mathrm{Cu}-\mathrm{Al}$ IMCs growth can be expressed in the following form:

$x=\left(1.2055 \times 10^{-7} \exp \left(\frac{-11681.7}{T}\right) t\right)^{\frac{1}{2}}$. 


\subsection{Lattice structure of $\mathrm{Cu}-\mathrm{Al}$ IMCs}

Cross sectional TEM specimens was prepared using lift-out technology with dual FIB which is capable to select small regions. The TEM micrograph from the sample that was thermally aged for $100 \mathrm{hrs}$ at $250{ }^{\circ} \mathrm{C}$ presents the morphology of the $\mathrm{Cu}-\mathrm{Al}$ IMCs region in Figure 8. Two layers IMC1 and IMC2 of IMCs were clearly observed between the copper ball and aluminium metallisation with each being approx. $700 \mathrm{~nm}$ in thickness.

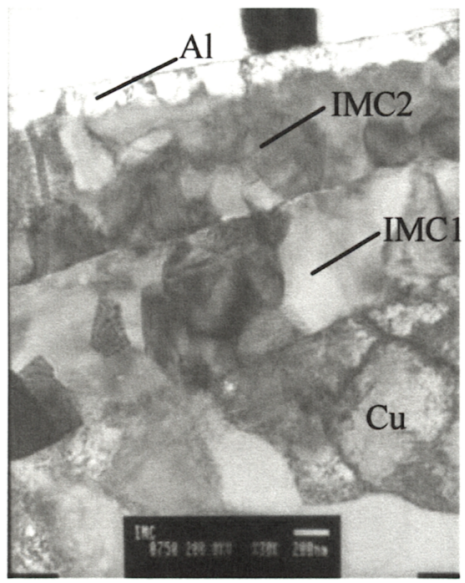

Figure 8 TEM image of the $\mathrm{Cu}-\mathrm{Al}$ interface after thermally aging for $100 \mathrm{hrs}$ at $250^{\circ} \mathrm{C}$

EDS analysis of IMC1 and IMC2 is summarized in Table 3. There are no significant changes in the composition of these two layers of $\mathrm{Cu}-\mathrm{Al}$ IMCs.

Due to the relatively large error in the TEM-EDS analysis, further confirmation of the formed IMCs was provided by selected area electron diffraction (SAD) for grains in two IMCs layers, presented in Figure 9a-b. Based on this SAD analysis, the IMC in both layers was $\mathrm{Cu}_{9} \mathrm{Al}_{4}$.

Table 3 EDS results for IMC1 and IMC2

\begin{tabular}{c|c|c}
\hline & IMC1 & IMC2 \\
\hline Cu K at.\% & 91.91 & 90.76 \\
\hline Al K at.\% & 28.09 & 29.24 \\
\hline
\end{tabular}
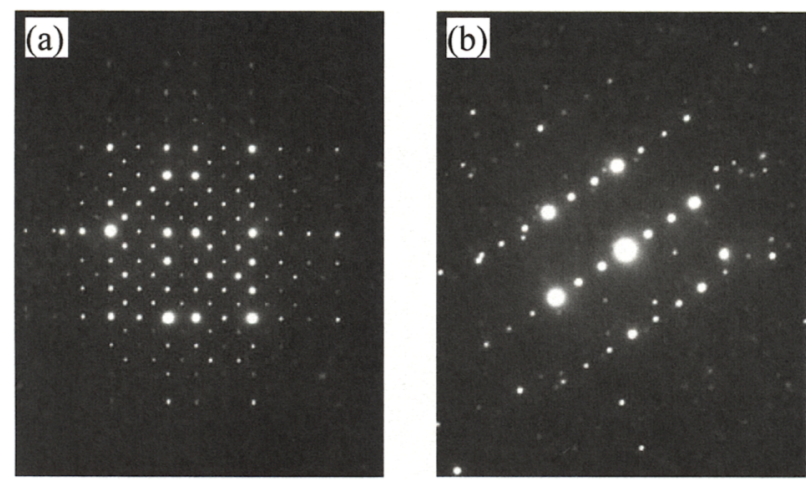

Figure 9 SAD of IMC1 (a), and IMC2 (b)

\section{Conclusions}

(1) Insignificant formation of $\mathrm{Cu}-\mathrm{Al}$ IMCs was found at the interface between copper ball and aluminium metallisation for as-bonded first copper bonds by SEMEDS analysis.

(2) Evolution of $\mathrm{Cu}-\mathrm{Al} \mathrm{IMCs}$ was linked to thermal aging. The $\mathrm{Cu}-\mathrm{Al} \mathrm{IMCs}$ growth follows the parabolic law as a function of annealing times at certain annealing temperatures.

(3) The growth rates of $\mathrm{Cu}-\mathrm{Al}$ IMCs formation for $200{ }^{\circ} \mathrm{C}, 250{ }^{\circ} \mathrm{C}$ and $300{ }^{\circ} \mathrm{C}$ were obtained by measuring IMCs thicknesses at those temperatures for different times, and the activation energy of $\mathrm{Cu}-\mathrm{Al}$ IMCs was calculated with the value $97.1 \mathrm{~kJ} / \mathrm{mol}$. An universal growth relation was derived for $\mathrm{Cu}-\mathrm{Al}$ IMCs, which is a function of the time and temperature.

(4) The phase of the $\mathrm{Cu}-\mathrm{Al}$ IMCs formed at the interface between copper ball and aluminium metallisation was confirmed to be $\mathrm{Cu}_{9} \mathrm{Al}_{4}$ by TEM-SAD analysis.

\section{Acknowledgments}

Authors would like to thank Prof. Zhong Chen from Nanyang Technological University, Singapore, and Mr. Honghui Wang, Mr. Xiaochun Wu, and Mr. Haiqing Zhu from Fujitsu-NT Ltd. China for their supports to this project.

\section{References}

1. Harman, G. G., Wire Bonding in Microelectronics, Materials, Processes, Reliability, and Yield. Second Edition. McGraw-Hill (New York; London, 1998).

2. Prasad, S. K., Advanced Wirebond Interconnection Technology, Springer (New York, 2004).

3. Philofsky E., "Intermetallic formation in goldaluminum systems". Solid State Electron, Vol. 13, No. 10, (1970), pp. 1391-1399.

4. Murali S., "Formation and growth of intermetallics in thermosonic wire bonds: Significance of vacancysolute binding energy", $J$ Alloys Comp, 2006, (426),pp. 200-204

5. Wulff F. W., et al, "Intermetallic Growth in Copper and Gold Ball Bonds on Aluminum Metallisation," $6^{\text {th }}$ Electronics Packaging Technology Conference, Singapore, December. 2004, pp.348-353

6. Murali, S., et al., "An Analysis of Intermetallics Formation of Gold and Copper Ball Bonding on Thermal Aging," MRS Bull. Vol. 38, No. 2 (2003), pp. 637-646.

7. Murali, S., et al, "Fundamentals of Thermo-sonic Copper Wire Bonding in Microelectronics Packaging," J Mater Sci, Vol. 42, No. 2 (2007), pp. 615-623.

8. Breach, C. D., Wulff, F. "New Oservations on Intermetallic Compound Formation in Gold Ball Bonds: General Growth Patterns and Identification of 
Two Forms of $\mathrm{Au}_{4} \mathrm{Al}$, Microelectronics Reliability, Vol. 44, No. 6 (2004), pp. 973-981

9. Braunovic, M., Alexandrov, N., "Intermetallic Compounds at Aluminum to Copper Electrical Interfaces: Effect of Temperature and Electric Current," IEEE Trans Comp Pack Manuf Technol Vol. A17, No. 1 (1994), pp. 78-85

10. Kim, H., "Effects of $\mathrm{Cu} / \mathrm{Al}$ Intermetallic Compound (IMC) on Copper Wire and Aluminum Pad Bondability," IEEE Trans-CPT, Vol. 26, No. 2 (2003), pp. 367-374.

11. Funamizu, Y., Watanabe, K., "Interdiffusion in Al$\mathrm{Cu}$ System," Tran Jpn Inst Metal, Vol 12, No. 3 (1971), pp. 147-152

12. Tamou, Y. et al., "Thermal and Ion Beam Induced Thin Film Reactions in Cu-Al Bilayers," Nucl. Instrum. Methods Phys. Res. Vol. B64, No. 1-4 (1992), pp. 130-133.

13. Rajan, K., Wallach, E. R. "A Transmission Electron Microscopy Study of Intermetallic Formation in Aluminum-copper Thin FilmCcouples," J. Crystal Growth, Vol. 49, No. 2 (1980), pp. 297-302. 